\title{
La producción de manuscritos iluminados en el entorno de la Curia Pontificia de Aviñón: un nuevo ejemplar conservado en Sevilla
}

\author{
Mercedes LÓPEZ-MAYÁN \\ Universidad de Santiago de Compostela \\ Departamento de Historia del Arte \\ mercedeslmn@gmail.com
}

\begin{abstract}
RESUMEN
Además de su trascendencia política y religiosa, la presencia de la Curia pontificia en Aviñón impulsó la creación artística al sostener, entre otras, una intensa producción de manuscritos. En las últimas décadas la historiografía ha progresado enormemente en el conocimiento de la miniatura elaborada en ese contexto; sin embargo, la enorme dispersión del fondo librario aviñonés hace que sigan siendo numerosos los manuscritos de esta procedencia que aún permanecen olvidados en archivos y bibliotecas de todo el mundo. En este artículo analizamos un nuevo hallazgo: un ejemplar de la Regula pastoralis conservado en Sevilla (BCC, ms. 56-1-1). Su importancia reside no solo en ser un testimonio de la iluminación aviñonesa ignorado hasta la fecha, sino en que, además, su aparato decorativo se puede relacionar con el presente en los pontificales de Vidal de Blanes y de Pedro de Luna, lo que enriquece nuestro conocimiento de los mecanismos de confección de manuscritos existentes en la ciudad del Ródano durante el siglo XIV y las primeras décadas del XV.
\end{abstract}

Palabras clave: miniatura; Aviñón; Regula Pastoralis; pontifical; Sevilla.

\section{The Production of Illuminated Manuscripts around the Papal Curia of Avignon: A New Example Kept in Seville}

\begin{abstract}
In addition to political and religious importance, the presence of Papal Curia in Avignon promoted artistic creation by supporting an intense production of manuscripts. In recent decades, the historiography has made substantial progress in the knowledge of the miniature produced in that period. However, due to the broad dispersion of the Avignonese books in archives and libraries all over the world, many manuscripts remain still unknown. In this paper we analyze a new finding: a copy of the Regula pastoralis kept in Seville (BCC, ms. 56-1-1). According to our conclusions, its importance is twofold. First, it is an unexplored example of the Avignonese illumination. Secondly, since its decoration is related to the miniature present in the pontificals of Vidal de Blanes and Pedro de Luna, it improves our understanding of the production of manuscripts in the city of the Rhone during the $14^{\text {th }}$ century and the first decades of the $15^{\text {th }}$.
\end{abstract}

Key words: miniature; Avignon; Regula Pastoralis; pontifical; Seville. 
La residencia del papado en Aviñón entre 1309 y 1429 es uno de los hitos más destacados de la historia de la cristiandad bajomedieval. Refugio frente a las disputas italianas entre güelfos y gibelinos desde tiempos de Clemente V (1305-1314) y, a partir de 1378, centro neurálgico del Cisma de Occidente, la ciudad del Ródano se convirtió no solo en una notable protagonista de la vida política, económica y eclesiástica de Europa, sino también en un dinámico foco de actividad intelectual y de creación artística ${ }^{1}$.

En este sentido y frente a la escasa atención que le había prestado la historiografía hasta los años sesenta del pasado siglo ${ }^{2}$, fue a partir de la celebración de sendas exposiciones (Avignon 1360-1410, comisariada por Marie-Claude Leonelli en 1978, y Les fastes du Gothique, realizada en París en 1981 a instancias de François Avril ${ }^{3}$ ) cuando comenzó a cambiar la percepción de la importancia de esa ciudad como foco fundamental de la miniatura gótica. Fruto de este nuevo interés, desde los años noventa del siglo XX se han multiplicado los estudios sobre la miniatura aviñonesa, cuya más reciente culminación es la monografía publicada por Francesca Manzari, quien ha reivindicado el peso de Aviñón como uno de los centros cuantitativa y cualitativamente más importantes en la producción de manuscritos iluminados durante el Trescientos e inicios del Cuatrocientos ${ }^{4}$. En paralelo, estos estudios han permitido alcanzar un mayor conocimiento de los rasgos de la miniatura originada en ese contexto, con una mejor delimitación de sus características estilísticas, lo que, a su vez, ha favorecido la identificación de nuevos códices o la atribución a este foco de ejemplares ya conocidos pero nunca antes relacionados con ese origen geográfico y cronológico ${ }^{5}$.

1 La literatura sobre el papado de Aviñón y sus implicaciones en muy diversos ámbitos de la historia del Occidente medieval es amplísima. Por ello, nos limitamos a remitir al lector a dos recientes obras de síntesis, en las que podrá encontrar nuevas referencias bibliográficas: FAVIER, Jean, Les papes d'Avignon, Paris, Le Gran Livre du Mois, 2006; PALADILHE, Dominique, Les papes en Avignon, Paris, Perrin, 2008.

2 Con la única excepción de los trabajos de LABANDE, Léon-Honoré, "Les manuscrits de la Bibliothèque d'Avignon provenant de la librairie des papes du XIV siècle", en Bulletin historique et philologique du Comité des travaux historiques et scientifiques, $\mathrm{n}^{\circ} 1-2,1894$, pp. 145-160; Idem, "Les miniaturistes avignonnais et leurs oeuvres", en Gazette des Beaux-Arts, nº 37, 1907, pp. 228 y 232-234; PANSIER, Pierre, Histoire du livre et de l'impression à Avignon du XIV au XV siècle, vol. I, Avignon, Aubanel, 1922.

3 Vid. sus respectivos catálogos: LÉONELLI, Marie-Claude (ed.), Avignon, 1360-1410: art et histoire, catalogue d'exposition (Avignon, 1978), Avignon, Centre International de Documentation et de Recherche du Petit Palais, 1978; AVRIL, François (coord.), Les Fastes du Gothique. Le siècle de Charles V, catalogue d'exposition (Paris, 1981-1982), Paris, Édition de la Réunion des Musées Nationaux, 1981.

4 MANZARI, Francesca, La miniatura ad Avignone al tempo dei papi (1310-1410), Modena, F. C. Panini, 2006; Idem, "Contributi per una storia della miniatura ad Avignone nel XIV secolo", en HAMESSE, Jacqueline (ed.), La vie culturelle, intellectuelle et scientifique à la Cour des papes d'Avignon, Turnhout, Brepols, 2006, pp. 111-140.

5 Entre las aportaciones más recientes, destacan MANZARI, Francesca, "Committenze di papi, cardinali e vescovi: nuove acquisizioni e considerazioni sulla miniatura avignonese del Trecento", en PLANAS BADENAS, Josefina y SABATÉ I CURULL, Flocel (eds.), Manuscrits il-luminats. L'escenografia del poder durant els segles baixmedievals, Lleida, Pagès Editors, 2010, pp. 43-66; Idem, "Mobilité des artistes et migrations de styles: les cours papales d'Avignon et de Rome durant le Grand Schisme", en DUBOIS, Jacques, GUILLÖUET, Jean-Marie y VAN DEN BOSSCHE, Benoît (dirs.), Les transferts artistiques dans l'Europe gothique. Repenser la circulation des artistes, des oeuvres, des thèmes et des savoir-faire (XII ${ }^{e}-X V I^{e}$ siècle), Paris, Picard, 2014, pp. 289-302. 
Una de las razones por las que el análisis de la producción manuscrita aviñonesa se ha mostrado enormemente complicado es la gran dispersión de los distintos códices confeccionados en ese núcleo, provocada, a su vez, por las peculiaridades de la actividad libresca que se desarrolló al socaire de la presencia papal. En efecto, el establecimiento permanente de la Curia en Aviñón desde tiempos de Juan XXII (1316-1334) generó una gran demanda de manuscritos puesto que la rica colección pontificia había quedado en Italia $-\mathrm{y}$, de hecho, solo sería trasladada parcialmente y en sucesivos años a la ciudad francesa $-{ }^{6}$. Esas necesidades se cubrieron gracias a la labor de copistas y miniaturistas procedentes del Norte y del Sur de Francia, de Cataluña, de Inglaterra y, sobre todo, de Italia; no en vano, muchos de ellos ya habían trabajado en suelo italiano para diversos cardenales y eclesiásticos, con los que después se desplazaron a la Corte aviñonesa, atraídos por las amplias posibilidades que ofrecía $^{7}$. Estas circunstancias determinaron el eclecticismo inicial de la iluminación aviñonesa, que solo a partir del estallido del Cisma adquirió unos rasgos estilísticos propios y definidos, de la mano de talleres tan importantes como el encabezado por Jean de Toulouse ${ }^{8}$. La reactivación de la producción en esos años continuó tras el ascenso de Benedicto XIII (1394-1418) a la cátedra de san Pedro. Este papa concedió, de hecho, gran importancia a la biblioteca pontificia: emprendió una reforma de gran envergadura en el palacio para albergar los libros, ordenó ampliar y corregir los catálogos existentes y se preocupó por el enriquecimiento tanto de los fondos de uso general como de los privados 9 . Ello no solo incrementó el volumen de encargos

6 MONFRIN, Jacques, "La bibliothèque pontificale au Moyen Âge", en Compte-rendu de la soixanteseptième session annuelle du Comité, Bruxelles, Union Académique Internationale, 1993, pp. 99-116, especialmente pp. 104-116; PARAVICINI BAGLIANI, Agostino, La Cour des Papes au XIII ${ }^{e}$ siècle, Paris, Hachette, 1995, pp. 196-197. Sobre la importante biblioteca papal del periodo anterior a la marcha a Aviñón, vid. el reciente trabajo de BILOTTA, Maria Alessandra, I libri dei Papi. La Curia, il Laterano e la produzione manoscritta ad uso del Papato nel Medioevo (secoli VI-XIII), Città del Vaticano, Biblioteca Apostolica Vaticana, 2011.

7 Uno de los casos más representativos es el del Maestro del Códice de San Giorgio. Miniaturista de origen toscano, activo en el primer cuarto del siglo XIV, su principal sede profesional fue, precisamente, Aviñón, donde trabajó, entre otros, para el poderoso cardenal Giacomo Stefaneschi (1206-1343). Vid., entre otros, MANZARI, Francesca, "Da Avignone a Roma: committenza e decorazione di alcuni codici liturgici", en MORELLO, Giovanni y MADDALO, Silvia (eds.), Liturgia in figura: codici liturgici rinascimentali della Biblioteca Apostolica Vaticana, catalogo della mostra (Città del Vaticano, 1995), Città del Vaticano, Biblioteca Apostolica Vaticana, 1995, pp. 59-65; CONDELLO, Emma, "Libri e committenza nella Roma del primo giubileo: i codici Stefaneschi e dintorni”, en RIGHETTI TOSTI-CROCE, Mario (ed.), Bonifacio VIII e il suo tempo: anno 1300, il primo Giubileo, catalogo della Mostra (Roma, 2000), Milano, Electa, 2000 , pp. 103-106; Idem, "Il libro e la Curia: copiste di codici e scriptores della Cancelleria pontificia tra Roma e Avignone", en HUBERT, Marie-Clotilde et alii (eds.), Le statut du scripteur au Moyen Age. Actes du XII Colloque Scientifique du Comité International de Paléographie Latine (Paris, 1998), Paris, École des Chartes, 2000, pp. 78-96.

8 Se trata del miniaturista mejor documentado de esta época y del que se conserva una abundantísima obra, incluyendo la lujosa serie de misales destinados al propio Clemente VII (1378-1394): MANZARI, Francesca, "Libri liturgici miniati nel palazzo di Avignone: tre serie di messali solemne per l'uso del papa", en QUINTAVAlle, Arturo Carlo (ed.), Medioevo: la Chiesa e il Palazzo. Atti del Convegno internazionale di Studi (Parma, 2005), Milano, Electa, 2007, pp. 604-611, especialmente pp. 604-607.

9 JULLIEN DE POMMEROL, Marie-Henriette y MONFRIN, Jacques La bibliothèque pontificale à Avignon et à Peñiscola pendant le Grand Schisme d'Occident et sa dispersion: inventaires et concordances, Roma, École Française de Rome, 1991, vol. I, pp. 12-49. 
a copistas y miniaturistas que eran contratados anualmente por la Curia, sino que, además, ejerció un efecto de llamada sobre eclesiásticos de toda la cristiandad que, aprovechando sus estancias en la Corte papal, se abastecieron de los libros que precisaban. Pero, significativamente, estos factores favorecieron también la dispersión de esa producción manuscrita: por un lado, en los viajes de regreso a las iglesias de origen de esos clérigos una vez terminado su cometido en Aviñón; por otro, a través de los avatares sufridos por la propia biblioteca pontificia tras el abandono de la urbe por Benedicto XIII hacia $1403^{10}$.

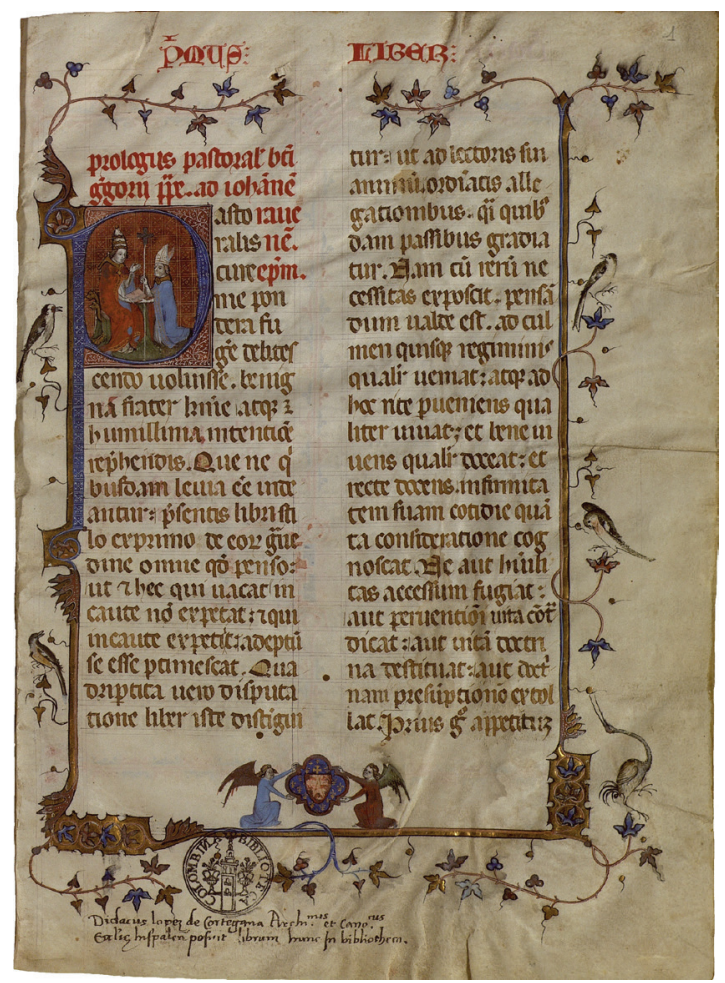

Fig. 1. Página de íncipit. Gregorio Magno, Regula pastoralis (Aviñón, XIV ex.-XV in.). Sevilla, BCC, ms. 56-1-1, f. 1r. (C) Biblioteca Capitular y Colombina de Sevilla.

Teniendo en cuenta estas circunstancias, no resulta sorprendente que hayamos identificado, entre los fondos de la Biblioteca Capitular y Colombina de Sevilla, un

10 Sobre la biblioteca de Benedicto XIII, vid. también GALINDO ROMEO, Pascual, La Biblioteca de Benedicto XIII, Zaragoza, Universidad de Zaragoza, 1929; PERARNAU I ESPELT, Josep, "Els inventaris de la Biblioteca papal de Peñíscola a la mort de Benet XIII", en Arxiu de Textos Catalans Antics, n 7, 1987, pp. 7-36; LAGUNA PAÚL, Teresa, "La biblioteca de Benedicto XIII", en SESMA MUÑOZ, José Ángel (ed.), Benedicto XIII, el Papa Luna. VII Muestra de Documentación Histórica Aragonesa en conmemoración del Sexto Centenario de la Elección Papal de Don Pedro Martínez de Luna (Aviñón, 28 septiembre 1394), catálogo de exposición (Zaragoza, 1994), Zaragoza, Gobierno de Aragón, 1994, pp. 75-90. 


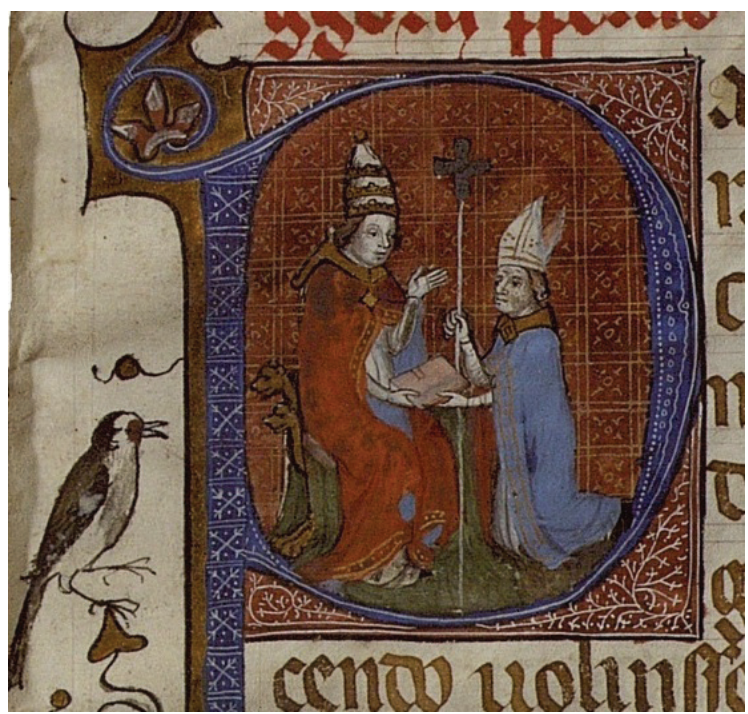

Fig. 2. Gregorio Magno entregando la regula a Juan, obispo de Rávena. Gregorio Magno, Regula pastoralis (Aviñón, XIV ex.-XV in.). Sevilla, BCC, ms. 56-1-1, f. 1r, detalle. C) Biblioteca Capitular y Colombina de Sevilla.

manuscrito al que apenas habían prestado atención los investigadores ${ }^{11}$ y que había pasado inadvertido a los historiadores de la miniatura aviñonesa cuando, sin embargo, se puede vincular con ese contexto de producción. Se trata del ejemplar 56-1-12, que contiene la Regula pastoralis de Gregorio Magno. Desconocemos la identidad de su destinatario porque las armas iluminadas en el margen inferior del $\mathrm{f}$. 1r han sido raspadas (fig. 1). Frente a ello, su materialidad y, sobre todo, su decoración constituyen los principales indicadores que nos permiten localizar su confección en Aviñón entre el final del siglo XIV y el comienzo del XV y, por esta vía, integrarlo en el amplio corpus de códices realizados en el complejo y fructífero foco de creación artística que fue la Curia pontificia durante su residencia en Francia.

El manuscrito presenta una factura material muy cuidada. Realizado en vitela, se compone de ciento cincuenta y ocho folios de 306 x $230 \mathrm{~mm}$, distribuidos en quiniones regulares ${ }^{13}$, y está escrito en una gótica textualis muy regular sobre pautado doble

11 Únicamente aparece recogido en el catálogo VERDUGO SANTOS, Javier (coord.), Las joyas de la Colombina. Las lecturas de Hernando Colón, Sevilla, Consejería de Cultura, 1989, p. 67, n 42, en el que se propone una posible datación en el siglo XV, sin indicación de lugar de origen, y, con una sucinta referencia, en la obra ÁLVAREZ MÁRQUEZ, Ma del Carmen, El libro manuscrito en Sevilla (siglo XVI), Sevilla, Ayuntamiento de Sevilla, 2000, p. 123. Sobre este manuscrito puede verse también la descripción disponible en el catálogo en línea de la Institución Colombina: http://213.97.164.119/ABSYS/abwebp.cgi/X5102/ID602/ $\mathrm{G} 0$ ?ACC=DCT3.

12 Olim BB 134-14, 81-6-1.

13 Con la excepción del quinto y del decimosexto cuadernos, que han perdido, en cada caso, un folio, con la consiguiente laguna en el texto. 


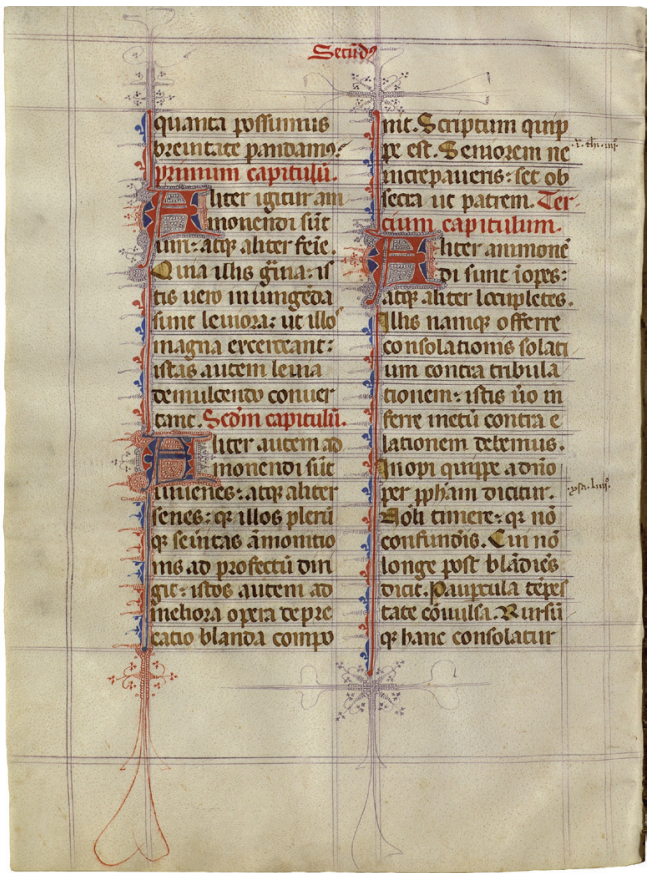

Fig. 3. Iniciales de filigrana. Gregorio Magno, Regula pastoralis (Aviñón, XIV ex.-XV in.). Sevilla, BCC, ms. 56-1-1, f. 50v. (C) Biblioteca Capitular y Colombina de Sevilla.

a tinta malva (fig. 3). Incluye reclamos horizontales, en negro e insertos en recuadros con decoración caligráfica, y titulus currens, en rojo, situado en el centro de los márgenes superiores. La encuadernación que presenta actualmente, en pergamino con correíllas, data del siglo XVII - cuando ya formaba parte de la institución sevillana- y se completa con guardas de papel verjurado blanco marcado con una filigrana cuya procedencia no hemos podido identificar ${ }^{14}$.

En lo que se refiere a su texto, contiene, como ya se indicó, la Regula pastoralis, escrita por el papa Gregorio Magno (ca. 590-604) entre septiembre de 590 y febrero de 591 como manual que recogía los preceptos sobre la moral y la predicación que debían observar los prelados; de hecho, se lo dedicó a Juan, obispo de Rávena (ca. 578-595). Su intención, en última instancia, era reforzar la unidad de la Iglesia y reformar su religiosidad en un momento de gran inestabilidad en Italia ante la invasión de los lombardos, de debilidad política del Imperio bizantino, escasamente presente en la Península Itálica, y de responsabilidad del papado como uno de los pocos poderes temporales que todavía eran operativos en la región de Roma ${ }^{15}$.

14 Tiene forma de óvalo y dos círculos superpuestos rematados por una corona: en el interior del óvalo, una cruz; en el círculo del medio, las iniciales $P P$; y en el círculo inferior, la inicial $O$.

15 JUDIC, Bruno, "Introduction", en JUDIC, Bruno y ROMMEL, Floribert (eds.), Grégoire le Grand, Règle pastorale, Paris, Éditions du Cerf, 1992, vol. I, pp. 15-112, especialmente pp. 15-22. Un estudio y 
Sin embargo, pese a haber sido elaborada en este contexto tan preciso, la obra alcanzó una enorme difusión por todo el Occidente cristiano ya en vida del propio Gregorio Magno. Con posterioridad y durante todos los siglos medievales, fue utilizada como manual de predicación, guía de buena conducta para los obispos y fuente de inspiración para la legislación sinodal, lo que también explica que adquiriese un nuevo impulso a raíz de la llamada Reforma gregoriana y continuase copiándose en las centurias siguientes, realizándose, incluso, traducciones al francés, al italiano o al castellano a partir del siglo XIV ${ }^{16}$. Como resultado de este gran éxito, la tradición textual y manuscrita de la Regula es enorme: no solo se conservan unos quinientos testimonios ${ }^{17}$, sino que, además, desde el siglo XV la obra comenzó a imprimirse, primero de manera aislada y, a partir de 1518, integrada en las Opera Omnia de san Gregorio, editadas como tales por primera vez en París por Berthold Rembolt ${ }^{18}$. No resulta extraño, por otra parte, que muchos de estos ejemplares se copiaran en Aviñón, pues residente fuera de Roma desde principios del Trescientos y, por tanto, alejado de la legitimidad que esta ciudad confería, el papado hubo de buscar en la reproducción y distribución de obras de destacado prestigio en la cristiandad el refrendo ideológico de su autoridad ${ }^{19}$.

Además de constituir un testimonio destacado de la Regula pastoralis, el manuscrito 56-1-1 sobresale por su refinada mise en page, que se concreta en un aparato ornamental sencillo pero muy cuidado y enormemente elocuente acerca del lugar y la fecha de su realización. Se compone principalmente de iniciales puzle en rojo y azul decoradas con filigranas en esos mismos colores y con festones geométricos que alcanzan todo el alto de la caja de escritura y dan lugar, en sendos extremos, bien a remates de filigrana, bien a espirales pobladas por ramilletes vegetales (fig. 3). Estas últimas se asemejan a las que presentan otros manuscritos aviñoneses, como el misal del cardenal Nicolás Rossell (1356-1362), escrito por Bernard de Toulouse hacia 1361 (Turín, Biblioteca Nazionale, ms. D.I.21, f. 423v) ${ }^{20}$. Pero, sobre todo, destaca

edición crítica más recientes de la Regula pastoralis puede consultarse en CREMASCOLI, Giuseppe (ed.), Regola pastorale, Roma, Città Nuova, 2008.

16 JUDIC, Bruno (1992), op. cit., pp. 88-102.

17 CLEMENT, Richard W., "A handlist of Manuscripts Containing Gregory's Regula Pastoralis", en Manuscripta, $\mathrm{n}^{\circ}$ 28, 1984, pp. 33-44. Nótese que este elenco no recoge el ejemplar que estudiamos.

18 JUDIC, Bruno (1992), op. cit., pp. 110-111.

19 Por la misma razón, proliferaron en la Curia francesa las copias de obras en las que se describían y ensalzaban las maravillas de Roma y la basílica del Vaticano y que servían, así, para reivindicar la vinculación con una ciudad físicamente lejana pero ideológicamente esencial en la eclesiología del pontificado aviñonés. Tal es el caso de Liber Politicus, escrito por Benedictus, canónigo de San Pedro, por encargo de Guido da Castello, futuro Celestino II (1143-1144) (vid. entre otros, FABRE, Paul, "Le Polyptique du chanoine Benoît. Étude sur un manuscrit de la Bibliothèque de Cambrai", en Travaux et mémoires des facultés de Lille, $\mathrm{n}^{\circ} 1$, 1889, pp. 1-36; VALENTINI, Roberto y ZUCCHETTI, Giuseppe, Codice topografico della Città di Roma, vol. 3, Roma, Tipografia del Senato, 1946, pp. 197-199), o del Liber Censuum, otra compilación fundamental sobre Roma y su basílica, elaborada a finales del siglo XII por Cencius con la intención de garantizar la correcta gestión de los bienes de la Iglesia romana (vid., entre otros, FABRE, Paul y DUCHESNE, Louis, Le liber censuum de l'Église romaine, Paris, A. Fontemoing, 1889-1910; MONTECCHI PALAZZI, Thérèse, "Cencius Camerarius et la formation du Liber Censuum de 1192", en Mélanges de l'École française de Rome. Moyen-Âge, Temps modernes, ${ }^{\circ}$ 96, 1984, pp. 49-93).

20 MANZARI, Francesca (2006a), op. cit., p. 173 y lám. 83. 


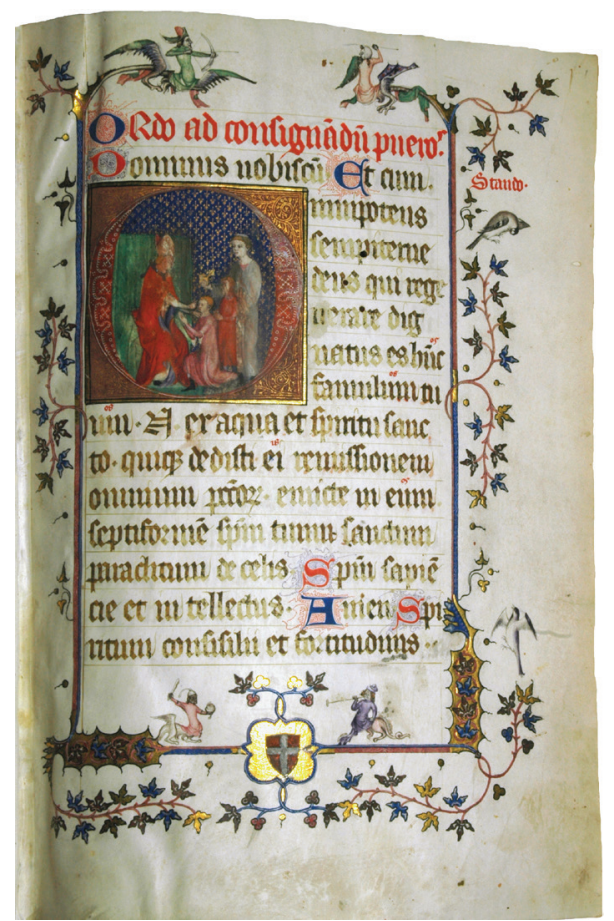

Fig. 4. Obispo confirmando a un niño y marginalia fantásticos. Pontifical de Vidal de Blanes, obispo de Valencia (Aviñón, ca. 1361-69). Valencia, Biblioteca Capitular, ms. 119, f. 1r.

(C) Biblioteca Capitular de Valencia.

la ornamentación del f. 1r, en el que una gran $P$ alberga la imagen del papa Gregorio Magno entregando su obra al obispo de Rávena, arrodillado ante él (figs. 1 y 2). Del cuerpo de la letra nacen delicados tallos que, inscritos en un fondo de oro, enmarcan toda la página, a modo de orla inicial, salpicada de hojas de parra y poblada por numerosos pájaros representados con gran naturalidad. En el centro del margen inferior, dos ángeles portan un medallón que alberga las armas del destinatario del manuscrito, lamentablemente desconocido.

$\mathrm{Su}$ léxico ornamental y sus rasgos estilísticos presentan claras similitudes con la decoración inicial de dos pontificales conservados en España: el de Vidal de Blanes, obispo de Valencia (1356-1369) (Valencia, Biblioteca Capitular, ms. 119) (fig. 4) y el de Pedro de Luna, arzobispo de Toledo (1404-1414) (Toledo, BCT, ms. Res. 9) (fig. 5). En los tres casos, las iniciales historiadas se disponen sobre recuadros decorados con filigranas vegetales en blanco y las escenas se sitúan sobre fondos monocromos con decoración geométrica. Igualmente, las figuras representadas muestran un tratamiento similar, aunque en el caso que estudiamos se alejan del dominio del sombreado que caracteriza las miniaturas del pontifical de Luna y se aproximan al de Blanes, cuyas figuras adolecen también de cierta rigidez (fig. 2). 
El paralelismo entre la Regula pastoralis y el manuscrito del prelado valenciano se hace especialmente evidente en las orlas que enmarcan sus folios iniciales (figs. 1 y 4), pues el diseño es absolutamente idéntico, incluso en la disposición de los tallos de los que nacen las hojas de parra. Solo difieren los medallones inferiores que contienen las armas de los respectivos propietarios -integrado en la orla en el pontifical de Blanes y portados por dos ángeles en el códice de Sevilla- y los marginalia que completan la decoración: en ambos casos se representan varios pájaros en distintas actitudes, pero, mientras que en el pontifical de Blanes predominan las escenas de combate entre seres híbridos, en la Regula pastoralis se observa un mayor realismo, que ha sustituido los motivos de drôlerie por un elevado número de aves, entre las que resuenan los ecos de la miniatura tolosana previa al establecimiento de la Curia en Aviñón en la garza que intenta atrapar un pequeño círculo de oro con su pico ${ }^{21}$. Desde este punto de vista, el manuscrito 56-1-1 se halla más cerca del pontifical de Luna, cuyos marginalia están dotados de un gran detallismo y vivacidad que se puede relacionar con la difusión del naturalismo de impronta lombarda en el tardogótico europeo a comienzos del siglo $\mathrm{XV}^{22}$. De hecho, algunos pájaros presentan el mismo perfil, procedente, quizá, de un mismo modelo ${ }^{23}$.

En función de estas semejanzas, es posible afirmar que el códice 56-1-1 fue realizado en un contexto próximo al de los dos pontificales mencionados, a saber, Aviñón entre mediados del siglo XIV y comienzos del XV. En efecto, sabemos que el primero fue encargado en la ciudad del Ródano por el prelado valenciano, que, no en vano, quiso que sus armas se iluminasen en el primer folio (fig. 4). Diversos autores han destacado que Vidal de Blanes tuvo que acudir a entrevistarse con el pontífice Inocencio VI (1352-1362) para evitar que su nombramiento como obispo de Valencia tras la muerte de su predecesor, Hugo de Fenollet (1348-1356), fuera invalidado, circunstancia que habría aprovechado para ordenar la realización de su manuscrito ${ }^{24}$. Sin embargo, en función de la mayor madurez de su miniatura con respecto a las obras aviñonesas de los años cincuenta, F. Manzari ha señalado que es más probable que el pontifical formase parte de la dotación litúrgica para la capilla del Santo Cáliz, que Blanes fundó en la catedral entre 1361 y 1369, lo que implicaría datar el códice en los años sesenta ${ }^{25}$. En todo caso, su adquisición se sitúa en un contexto marcado

21 Este motivo, típico de la miniatura de Toulouse entre finales del siglo XIII y principios del XIV, es, de hecho, frecuente en los primeros productos manuscritos de la Curia pontificia y apunta a la importante -y lógica- influencia de la iluminación del Midi en ellos: MANZARI, Franceca (2006a), op. cit., pp. $27-$ 28. Varias aportaciones más recientes sobre esta cuestión pueden consultarse en CASSAGNES-BROQUET, Sophie y FOURNIÉ, Michelle (eds.), Le livre dans la région toulousaine et ailleurs au Moyen Âge, Toulouse, CNRS-Université de Toulouse-Le Mirail, 2010.

22 MANZARI, Francesca (2006a), op. cit., p. 327.

23 Compárese, por ejemplo, el pájaro superior del margen derecho de la Regula pastoralis con el que aparece en la parte inferior del margen izquierdo del pontifical de Luna (figs. 1 y 5).

24 VILLALBA DÁVALOS, Amparo, La miniatura valenciana en los siglos XIV y XV, Valencia, Institución Lorenzo el Magnánimo, 1964, p. 37; RAMÓN MARQUÉS, Nuria, La iluminación de manuscritos en la Valencia gótica (1290-1458), Valencia, Generalitat Valenciana, 2007, p. 37.

25 MANZARI, Francesca (2006a), op. cit., p. 162. Una descripción del contenido de este pontifical puede consultarse en también JANINI, José, Manuscritos litúrgicos de las bibliotecas de España, Burgos, Aldecoa, 1977, vol. II, p. 292. 


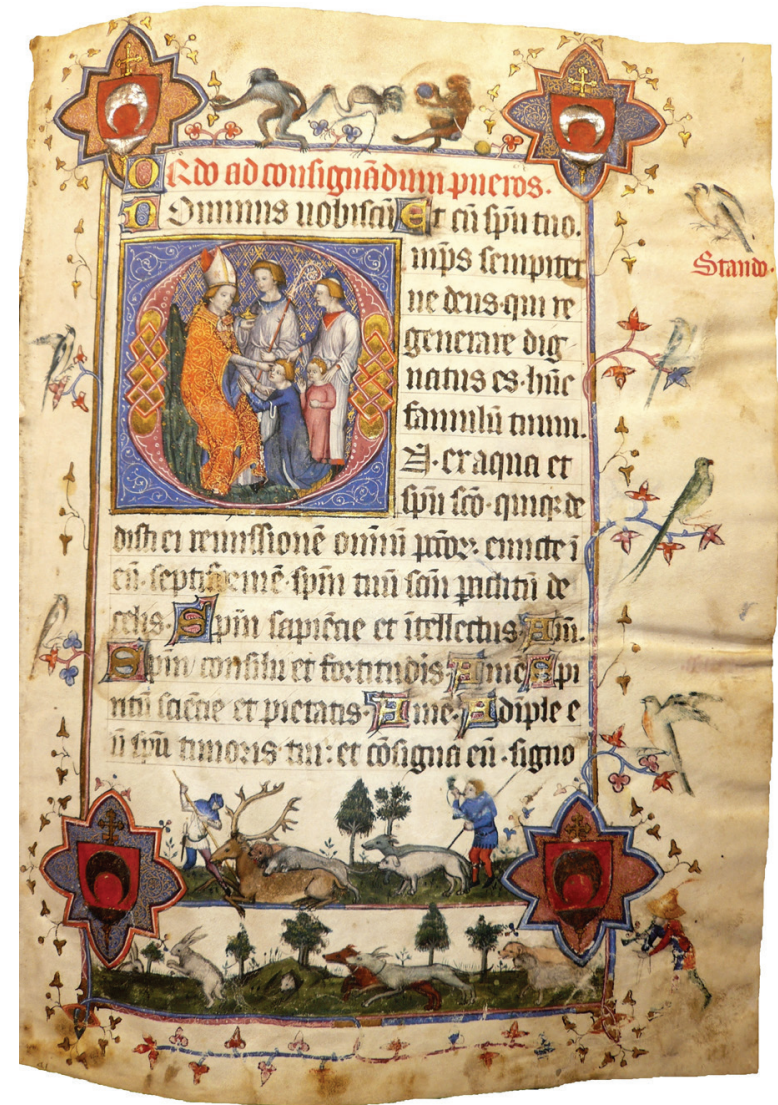

Fig. 5. Obispo confirmando a un niño; en los márgenes, drôleries de caza y armas de los Luna. Pontifical de Pedro de Luna, arzobispo de Toledo (Aviñón, ca. 1403). Toledo, BCT, ms. Res. 9, f. 1r. C Biblioteca Capitular de Toledo.

por la estrecha vinculación de la diócesis valenciana con la Curia francesa ${ }^{26}$ y por un destacado auge económico vivido en esta región desde mediados del siglo XIV y que, desde el punto de vista artístico, sostuvo un periodo de esplendor y propició la llegada a Valencia de obras y artistas procedentes de diferentes zonas del Occidente europeo $^{27}$.

26 CÁRCEL ORTÍ, Vicente, "La diócesis de Valencia durante la plenitud del medioevo (1238-1499)", en CÁRCEL ORTÍ, Vicente (coord.), Iglesias de Valencia, Segorbe-Castellón y Orihuela-Alicante, Madrid, Biblioteca de Autores Cristianos, 2006, pp. 53-180, especialmente pp. 113-122.

27 En lo que se refiere a la iluminación de manuscritos, se sitúa en estos años la actividad de artistas tan destacados como Simón Despuig, Mateo Terres y Domingo Crespí, responsables de la asimilación de las tendencias francesas y catalanas que está en la base del nacimiento de la miniatura valenciana: RAMÓN MARQUÉS, Nuria (2007), op. cit., p. 35. Vid. también MIQUEL JUAN, Matilde y SERRA DESFILIS, Amadeo, "Se embellece toda, se pinta con pintura de ángeles. Circulación de modelos y cultura pictórica 
En lo que se refiere al manuscrito Res. 9 de la Biblioteca Capitular de Toledo (fig. 5), a partir de su análisis estilístico e iconográfico F. Manzari ha establecido que fue realizado en Aviñón hacia 1403 y ha planteado la hipótesis de que, pese a que las armas iluminadas en los medallones del f. 1r son las de Benedicto XIII ${ }^{28}$, su destinatario fue, en realidad, su sobrino, Pedro de Luna, al que aquél nombró arzobispo de Toledo en 1404, si bien no pudo acceder a la sede hasta principios de 1407 por las reticencias de Enrique III de Castilla (1390-1406) ${ }^{29}$. Solo cuando la corona quedó en manos de la reina viuda, Catalina de Lancaster, y del hermano del monarca, Fernando de Antequera -futuro Fernando I de Aragón (1412-1416)-, el papa consiguió hacer valer su opción y los regentes nombraron a Pedro de Luna como arzobispo toledano en una clara muestra de acercamiento a la causa aviñonesa en el momento en que, tras la elección de un nuevo papa romano, Gregorio XII (1406-1415), los reinos europeos empezaban a convencerse de que la única forma de acabar con el Cisma era la vía conciliar $^{30}$.

Parece, por lo tanto, evidente que el manuscrito 56-1-1 de la biblioteca sevillana fue realizado en Aviñón por parte de alguno de los talleres responsables del abastecimiento de la Curia papal y de los eclesiásticos de diversa procedencia que la frecuentaban. Es más, considerando que presenta un modelo decorativo idéntico al del ejemplar de Vidal de Blanes pero estilísticamente más evolucionado y próximo al códice de Luna, resulta verosímil considerar que hubo de ser confeccionado entre los años finales del siglo XIV y los primeros del XV, coincidiendo con la época de mayor esplendor de este foco artístico.

Además del establecimiento de sus coordenadas de origen, su similitud con los dos pontificales mencionados conduce a una cuestión fundamental acerca de la producción manuscrita desarrollada alrededor de la Curia francesa: ¿es posible considerar que los tres ejemplares fueron realizados por el mismo taller? Conviene tener presente, en este sentido, que los códices de Blanes y Luna fueron iluminados por artistas diferentes, cuya identidad desconocemos, pero que formaban parte de un mismo taller que se mantuvo activo en Aviñón durante cuatro décadas, entre, aproximadamente, 1360 y 1403 . Así se infiere de las imágenes que albergan las iniciales historiadas,

en la Valencia de 1400", en Artigrama. Revista del Departamento de Historia del Arte de la Universidad de Zaragoza, $\mathrm{n}^{\circ} 26,2011$, pp. 333-380.

28 Idéntica heráldica ostentan otros muchos manuscritos realizados para este pontífice de fuerte personalidad bibliófila y letrada, como ya se comentó. Tal es el caso del misal en dos volúmenes (Ciudad del Vaticano, BAV, Vat. lat. 4764 y Vat. lat. 4765), realizado hacia 1411, después del abandono definitivo de Aviñón y el establecimiento en Perpiñán (MANZARI, Francesca (2007), op. cit., pp. 607-609); las Vitae Romanorum Pontificium (París, BNF, lat. 5142), escritas en Aviñón pero iluminadas en Cataluña a principios del siglo XV (MANZARI, Francesca (1995), op. cit., p. 63); o el pontifical conservado en París, BNF, ms. lat. 968, cuya iluminación, originalmente inacaba, fue completada en esos años por el miniaturista catalán Sancho Gontier (AVRIL, François, "Manuscrits", en AVRIL, François (coord.) (1981), op. cit., pp. 276-362, especilamente pp. 356-357, no 313; MANZARI, Francesca (2006a), op. cit., pp. 273-276). Además, puede consultarse la digitalización de los folios iluminados de estos dos últimos manuscritos en la web de la Banque d'images de la BNF: http://images.bnf.fr/jsp/index.jsp.

29 MANZARI, Francesca (2006a), op. cit., pp. 162-167. Para una descripción del texto de este pontifical, vid. JANINI, José y GONZÁLVEZ, Ramón, Catálogo de los manuscritos litúrgicos de la Catedral de Toledo, Toledo, Diputación Provincial, 1977, pp. 265-267, no 240.

30 ÁlVAREZ PAlENZUELA, Vicente Á., El Cisma de Occidente, Madrid, Rialp, 1982, p. 184. 
cuyos diseños son muy similares, con igual forma de las vestimentas, la misma delicadeza de los gestos y de las posturas, idéntica disposición del pelo, similares fondos planos con decoración de filigrana, etc. También el léxico ornamental ofrece, como ya se comentó, un evidente parentesco, especialmente visible en las respectivas páginas de íncipit: ambas poseen la misma mise en page, con una primera rúbrica en rojo, seguida del ordo de la confirmación del niño, con su correspondiente inicial historiada inserta en un recuadro bordeado en oro; alrededor, una sutil cenefa geométrica encuadra el texto y se decora con hojas de parra; sobre ella, tanto en el margen superior como en el inferior, habitan diversas drôleries y, en su contorno, cobran vida, en las más diversas posturas, varios pájaros. No obstante, las figuras del pontifical de Vidal de Blanes son mucho más toscas y rígidas que las del ejemplar de Luna, del mismo modo que las hojas de parra y los animales que pueblan la cenefa están realizados con mucho mayor naturalismo en este último caso que en el manuscrito del prelado valenciano. Ello es consecuencia de la distancia temporal existente entre ambos códices, que representarían, por tanto, gli estremi cronologici della produzione di una bottega avignonese di cui non conosciamo, per ora, nessuna altra opera ${ }^{31}$.

El manuscrito 56-1-1 fue iluminado, sin duda, por un miniaturista diferente y, además, en él intervino un artista responsable de las delicadas iniciales de filigrana, que no trabajó en los libros de los prelados hispanos. No obstante, las similitudes estilísticas y, sobre todo, ornamentales entre los tres ejemplares son, según se apuntó, muy notables, basadas, incluso, en la utilización de un mismo modelo decorativo. No parece que esta circunstancia sea suficiente para atribuir su realización al mismo taller aviñonés, máxime si consideramos que, en ese contexto de gran dinamismo de la producción manuscrita, no debió de ser infrecuente la circulación de modelos entre los artistas y talleres que trabajaban en la ciudad. Por ello y ante la imposibilidad de identificar a su destinatario original por el mal estado de las armas iluminadas en el primer folio solo cabe plantear la hipótesis - que quizás futuros hallazgos contribuirán a esclarecer-de que la Regula pastoralis 56-1-1 pudiera haber sido elaborada por el mismo taller que ejecutó los dos pontificales, uniéndose, así, a la reducida nómina de códices a él debidos que se conocen hasta la fecha.

Lo que sí es evidente, en todo caso, es que, perteneciera o no al mismo taller, el miniaturista que ilustró este manuscrito trabajó en su entorno y estuvo estrechamente vinculado a él, hasta el extremo de emplear unos modelos decorativos idénticos. En consecuencia, este ejemplar, hasta ahora ignorado, constituiría la primera evidencia de que, alrededor del taller de larga vida al que se han atribuido los dos pontificales, existió una actividad de producción, coincidiendo con el momento de máxima eclosión de la miniatura aviñonesa y en paralelo al trabajo de artistas tan destacados como el ya citado Jean de Toulouse. En este contexto, fue, asimismo, significativa la actividad de miniaturistas y copistas peninsulares ${ }^{32}$, al igual que fueron numerosos

31 MANZARI, Francesca (2006a), op. cit., pp. 164-167.

32 Tal es el caso del iluminador Sancho Gonthier, que colaboró con el propio Jean de Toulouse en algunos códices, como las Vitae Romanorum Pontificium (París, BNF, lat. 5142), o el calígrafo catalán Antonio Sánchez, que dejó su firma en una Historia ecclesiastica de Tolomeo da Lucca (París, BNF, ms. lat 5126, f. 1): MANZARI, Francesca (2006a), op. cit., pp. 273-284. Puede consultarse la digitalización de los folios 
los eclesiásticos hispanos que encargaron manuscritos iluminados ${ }^{33}$. Hay que tener en cuenta que los contactos de las Iglesias castellana y aragonesa con la Corte ultrapirenaica fueron continuos desde tiempos de Juan XXII ${ }^{34}$ y se acentuaron a raíz del estallido del Cisma: en el primer caso, el clero de Castilla se adhirió oficialmente a la obediencia aviñonesa en la asamblea de Salamanca de 1381, presidida por el monarca Juan I Trastámara (1379-1390) ${ }^{35}$; en el segundo, fue decisivo el ascenso al solio papal de un aragonés, Pedro Martínez de Luna, con el nombre de Benedicto XIII ${ }^{36}$. No resultaría, en consecuencia, sorprendente que el manuscrito 56-1-1 hubiera sido encargado en Aviñón por un clérigo peninsular; sin embargo, según se ha apuntado, en el estado actual de nuestro conocimiento resulta imposible conocer la identidad de su destinatario y propietario original.

Sí sabemos, por el contrario, que, en la transición del siglo XV al XVI, el manuscrito perteneció a Diego López de Cortegana (1455-1524); así lo indica la anotación añadida en el margen inferior del f. 1r: Didacus Lopez de Cortegana, archidiaconus et canonicus Ecclesie Hispalensis, posuit librum hunc in bibliotheca (fig. 1). Además de arcediano de Sevilla, este personaje ostentó los cargos de fiscal del Tribunal del Santo Oficio de la Inquisición en 1498 y capellán de Isabel la Católica (1474-1504). Destacó, además, por su espíritu y formación humanista, que le llevó a traducir varias obras de Apuleyo, Erasmo y Eneas Silvio Piccolomini y a poseer una importante biblioteca, entre cuyos volúmenes se contaban otros dos manuscritos conservados actualmente en la biblioteca sevillana: un ejemplar del De consideratione de san Bernardo de Claraval (Sevilla, BCC, ms. 57-1-22) y los Sententiarum libri IV de Pedro Lombardo (Sevilla, BCC, ms. 56-5-5) ${ }^{37}$.

iluminados de estos últimos manuscritos en la web de la Banque d'images de la BNF: http://images.bnf.fr/ jsp/index.jsp.

33 Uno de los casos más significativos fue el de Juan de Villacreces, obispo de Calahorra y La Calzada (1382-1394), quien, en 1390, encargó al famoso taller de Jean de Toulouse la elaboración de un lujoso pontifical (Sevilla, BCC, ms. BB 149-3). Sobre este manuscrito, vid., entre otros, JANINI, José (1977), op. cit., vol. I, pp. 280-285, $\mathrm{n}^{\circ}$ 341; ÁLVAREZ MÁRQUEZ, $\mathrm{M}^{\mathrm{a}}$ del Carmen, El mundo del libro en la Iglesia Catedral de Sevilla en el siglo XVI, Sevilla, Diputación Provincial, 1992, pp. 107-109 y 133-134; PLANAS, Josefina, El esplendor del Gótico catalán. La miniatura a comienzos del siglo XV, Lleida, Estudi General, 1998, pp. 59-60; MANZARI, Francesca (2006a), op. cit., pp. 10, 15, 181, 249-252, 257, 260, 264, 352, 353 y figs. 126128; Idem (2010), op. cit., pp. 60-61; LÓPEZ-MAYÁN, Mercedes, "Liturgia, manuscritos y poder en la Edad Media. Estudio de los pontificales en el antiguo Reino de León y Castilla", Tesis doctoral, Universidad de Santiago de Compostela, 2013, pp. 766-790, n ${ }^{\circ}$ 35; Idem, "Los pontificales en Castilla durante la Edad Media: aproximación a una fuente de conocimiento histórico", en MIRANDA, Flávio, SEQUEIRA, Joanna, FARIA, Diogo (eds.), Incipit 2. Workshop de Estudos Medievais da Universidade do Porto, 2011-2012, Oporto, Universidade do Porto, Facultade de Letras, Biblioteca Digital, 2014, pp. 141-153, especialmnete pp. 151-153.

34 Para una primera aproximación, vid. FERNÁNDEZ CONDE, Javier y OLIVER, Antonio, "La Corte pontifica de Aviñón y la Iglesia española”, en FERNÁNDEZ CONDE, Javier (dir.), La Iglesia en la España de los siglos VIII al XIV, Madrid, Biblioteca de Autores Cristianos, 1982, pp. 359-415, especialmente pp. 375-383.

35 FERNÁNDEZ CONDE, Javier y OLIVER, Antonio, "El Cisma de Occidente y los reinos peninsulares", en FERNÁNDEZ CONDE, Javier (dir.), La Iglesia en la España de los siglos VIII al XIV, Madrid, Biblioteca de Autores Cristianos, 1982, pp. 463-495, especialmente pp. 465-477.

36 SESMA MUÑOZ, José Ángel (ed.) (1994), op. cit.; SUÁREZ FERNÁNDEZ, Luis, Benedicto XIII: ¿antipapa o papa? (1328-1423), Barcelona, Ariel, 2002.

37 ÁlVAREZ MÁRQUEZ, Ma del Carmen, op. cit., p. 123. Sobre la obra y personalidad de Diego López de Cortegana, vid. ÁLVAREZ DÍAZ, María, "Las traducciones del Asinus aureus de Apuleyo: estudio 
¿Cómo fue a parar el códice de Aviñón a Sevilla? Carecemos de documentación precisa al respecto; no obstante, sabemos que, antes de ser promovido a la sede de Toledo en 1403, Pedro de Luna fue arzobispo de Sevilla (1401-1403), con lo que es posible que hubiera adquirido en la ciudad francesa la Regula pastoralis, fabricada para otro destinatario anterior, y la hubiese trasladado a Sevilla. Y, quizá, el contacto con este ejemplar le sirvió para conocer ciertos modelos ornamentales que luego hizo copiar en su pontifical, una vez nombrado arzobispo de Toledo. De esta manera, sería posible conjeturar que el parentesco entre el pontifical de Vidal de Blanes y el del Luna no se deba a un contacto directo entre ambos manuscritos, difícil de explicar dada su distancia cronológica ${ }^{38}$, sino a través de la intermediación del ejemplar 56$1-1$.

Futuras investigaciones permitirán, sin duda, arrojar más luz sobre estas cuestiones que, en la actualidad, solo podemos apuntar como meras hipótesis. Es, asimismo, muy probable que, en los próximos años, se identifiquen como productos aviñoneses manuscritos desconocidos hasta el momento o erróneamente atribuidos a otros talleres o escuelas. Y quizás entonces dispongamos de nuevas evidencias que permitan comprender mejor la historia de la Regula pastoralis conservada en Sevilla y, por esta vía, profundizar y completar nuestro conocimiento sobre el complejo y riquísimo panorama de producción manuscrita que fue la Curia papal y su entorno durante el tiempo que residió en Francia.

comparativo y atención especial a la versión de Diego López de Cortegana", Tesis doctoral, Universidad de Oviedo, 1998; ESCOBAR BORREGO, Francisco Javier, "Diego López de Cortegana, traductor del Asinus Aureus: el cuento de Psique y Cupido", en Cuadernos de Filología Clásica. Estudios latinos, n 22, 2002, pp. 193-209; y, más recientemente, ESCOBAR BORREGO, Francisco Javier, DÍEZ REBOSO, Samuel y RIVERO GARCÍA, Luis (eds.), "Metamorfosis" de un inquisidor: el humanista Diego López de Cortegana (1455-1524), Huelva, Universidad de Huelva, 2013.

38 MANZARI, Francesca (2006a), op. cit., p. 165. 